\title{
Humanização no atendimento ao paciente idoso em unidade de terapia intensiva: análise da literatura sobre a atuação do profissional de saúde
}

Humanization of the patient in the intensive care unit: a review of the literature on the role of health professional

\author{
Geórgia Pires Assunção* \\ Raquel Aline Fernandes*
}

\begin{abstract}
Resumo:
Este estudo trata-se de uma revisão bibliográfica, cujo objetivo é identificar, na literatura, as dificuldades enfrentadas pelos profissionais de saúde, com relação ao cuidado humanizado, no âmbito hospitalar, especificamente em UTI (Unidade de Terapia Intensiva) - local culturalmente desconhecido, incerto e temível aos pacientes e seus familiares. Esta revisão também visa contribuir para a melhoria da assistência ao paciente idoso internado. Humanizar tem como objetivo aprimorar as relações humanas em todos os níveis de atendimento, levando à melhoria do relacionamento entre equipe de saúde, pacientes e familiares. 0 acolhimento é uma estratégia usada para se obter um melhor atendimento ao paciente, visando estabelecer vínculos de credibilidade e confiança, onde 0 profissional de saúde deverá assumir uma postura adequada, capaz de atender a todas as necessidades.
\end{abstract}

Palavra-chave: Humanização; Humanização em Uti; Cuidado; Acolhimento, idoso.

\begin{abstract}
:
This study is a bibliographic revision which aims to identify in literature the difficulties faced by health professionals concerning humanized care in the hospital ambient, specifically in Intensive Care Units - ICU's. The ICU is an unknown, uncertain and feared place for the patients and their families. Furthermore, this document also aims to contribute to the improvement of interned elderly patients assistance. Humanizing has as its objective the improvement of human relationships in all assistance levels: medical staff, patients and their families. How well the patient is received is a strategy used in order to obtain better care of the patient aiming at the establishment of the credibility and trust in which the health professional must assume an appropriate behavior, capable of fulfilling all the patients requirements.
\end{abstract}

Key words: Humanization; Humanization in the ICU; Care; Reception; Elderly.

\footnotetext{
*Graduada em Serviço Social (UNICAP-PE); Pós-graduanda em Saúde do Idoso do Instituto de Ciências Biológicas (UPE); Assistente Social da Unimed Recife georgiapires@yahoo.com.br

** Mestre em Cirurgia Vascular (UFPE); Pós-graduada em Administração de Serviços de Saúde (UPE) raquel1108@gmail.com
} 


\section{Introdução}

Durante a vida, o ser humano procura várias maneiras de melhoria pessoal. Profissionais de saúde vivenciam experiências por muitas vezes traumáticas, refletindo assim, em suas ações na assistência ao paciente. Na arte do cuidar há vários caminhos a serem percorridos, e apesar de todo o esforço da equipe para humanizar o atendimento, esta é uma tarefa difícil, pois demanda, às vezes, atitude individual em relação a um sistema tecnológico dominante.

Knobel (1998) diz que: "a humanização é um antigo conceito que renasce para valorizar as características do gênero humano. Para que seja verdadeiramente recuperado, é necessária uma equipe consciente dos desafios a serem enfrentados e dos próprios limites a serem transpostos".

A hospitalização é uma situação delicada porque implica em mudanças na vida do doente e seus familiares, gerando ansiedade pela exposição a um ambiente estressante, necessitando de apoio dos profissionais que compõem o serviço. (FAQUINELO, HIGARASHI; MARCON, 2007; FAQUINELO; COLLET, 2003). Esse fato representa para muitos idosos um momento de fragilidade, medo e insegurança, sendo mais intensificado quando ocorre na UTI, que é totalmente diferente da sua residência. (MARTINS; NASCIMENTO, 2005). Refletir sobre o cuidado ao idoso internado em UTI é importante devido ao grande contingente da população idosa que por algum motivo hospitaliza-se.

O cuidado humanizado não é uma técnica ou artifício, mas uma vivência a perpassar toda atividade dos profissionais com propósitos de oferecer e realizar o melhor tratamento ao ser humano. Consiste na compreensão e na valorização da pessoa, considerando acima de tudo que haja sensibilização por parte da equipe com relação à problematização da realidade. (BACHES; LUNARDI FILHO; LUNARDI, 2005). Além de envolver o cuidado ao paciente, estende-se a todos aqueles que estão envolvidos no processo saúde-doença, que são: a família, a equipe multidisciplinar e o ambiente. Quando o paciente é idoso, é necessário o preparo técnico e acolhimento humanizado para o cuidado integral a este ser, não esquecendo que deve haver cumplicidade entre os envolvidos para uma melhor qualidade na assistência. 
A parceria entre equipe e família retrata a valorização da qualidade do atendimento, característica essencial do cuidado humanizado. Pequenos gestos demonstrando respeito e atenção, de forma igualitária fazem a diferença no atendimento.

Resgatar a humanização talvez seja refletir mais conscientemente sobre o que é o ser humano, respeitando suas necessidades, seus valores, suas crenças e de seus familiares, tendo sua privacidade preservada sempre que possível, proporcionando condições e ambientes favoráveis, com tratamento digno, solidário e acolhedor ao seu restabelecimento, e em última instância, a morte digna. (CAETANO; ANDRADE; SOARES, PONTE, 2007; BOFF, 2004; BACKES; LUNARDI; LUNARDI FILHO, 2006) O compromisso com a humanização no ambiente hospitalar não deve ser considerado um ato passivo, pois requer um processo permanente e gradual de ação e inserção na realidade, através do esforço dinâmico e participativo.

No Brasil, as primeiras UTIs foram implantadas na década de 1970 e se tornaram unidades especializadas e consideradas como de alta complexidade. Assim, houve necessidade de aperfeiçoamento dos profissionais e também, obtenção de equipamentos cada vez mais modernos e sofisticados. Os serviços de terapia intensiva ocupam áreas hospitalares destinadas ao atendimento de pacientes críticos que necessitem de cuidados complexos e especializados. (GARANHANI; MARTINS; ROBAZZ; GOTELIPE, 2008)

A UTI nasceu da necessidade de oferecer suporte e tratamento a pacientes potencialmente graves que porventura possuam chances de sobreviver, destina-se a internação de pacientes com instabilidade clínica e com potencial de gravidade. É um ambiente de alta complexidade, reservado, já que se propõe estabelecer monitorização e vigilância contínua, com a grande preocupação em fornecer conforto e ausência de dor a todos os pacientes.

O ambiente da UTI pode ser considerado fonte de estresse, que envolve tanto paciente quanto a equipe de saúde, gerando às vezes distúrbios psíquicos e fisiológicos importantes.

Para Lopes e Laufert (2001) o ambiente da UTI é caracterizado por um trabalho que envolve uma forte carga emocional, no qual vida e morte se misturam, compondo um cenário desgastante e, muitas vezes, frustrante. ( LOPES; LAUFERT, 2001) Estando na UTI, o paciente idoso sofre alterações físicas, psicológicas e sociais e passa à dependência de 
terceiros para seus cuidados tornando mais difícil a sua adaptação. Para PEDREIRA (2001), os idosos podem apresentar mudança de comportamento como agitação, desorientação, negação ao tratamento, pois no envelhecimento acontece a perda da capacidade de entendimento das mudanças, o que dificulta ainda mais a sua aceitação ao ambiente de terapia intensiva.

Assim, o objetivo deste estudo é identificar as dificuldades encontradas pelos profissionais de saúde no processo da assistência humanizada aos pacientes idosos em UTI. Trata-se de um estudo descritivo, de natureza qualitativa, cujo material de pesquisa foi o levantamento bibliográfico, sendo a seleção feita por meio de busca ativa em livros, periódicos e artigos, submetidos a uma análise do conteúdo. Foram utilizadas palavraschaves como humanização, humanização em UTI, cuidado, acolhimento, idoso.

\title{
Envelhecimento
}

\begin{abstract}
O envelhecimento é um processo natural da vida humana, trazendo consigo uma série de modificações biopsicossociais, que alteram a relação do homem como meio no qual está inserido. O processo de envelhecimento é muito pessoal, constitui uma etapa da vida com realidades próprias e diferenciadas das anteriores, limitadas unicamente por condições objetivas e subjetivas (DANTAS, 2005)
\end{abstract}

Alvarez (2001) afirma que alguns fatores que contribuíram para o aumento no número de idosos no Brasil, são aqueles relacionados principalmente com a melhoria das condições de vida da população, os progressos na medicina e pela inovação tecnológica. Isso significa que, as pessoas vivendo mais tempo podem necessitar com maior frequência dos serviços de saúde.

O Instituto Brasileiro de Geografia e Estatística (IBGE), sugere que a população idosa chegue a 64 milhões de pessoas em 2050, o que corresponderia a $24,6 \%$ do total de habitantes.

O estatuto do idoso em seu artigo 18 coloca que "as instituições de saúde devem atender aos critérios mínimos para atendimento ao idoso, promovendo o treinamento e a capacitação dos profissionais, assim como orientação a cuidadores e grupos de autoajuda." (BRASIL, 2003). Desta forma, há necessidade de qualificar os profissionais de saúde para um atendimento acolhedor, respeitando suas peculiaridades. 


\section{Humanização em UTI}

No âmbito hospitalar, a UTI é vista como um dos locais mais tensos e traumatizantes, concentrando pacientes em estado crítico, com necessidade de observação constante e cuidados especiais. Embora possua mecanismos tecnológicos utilizados cada vez mais avançados, somente este aparato não contribui para melhor eficácia do tratamento e uma assistência de qualidade e humanizada. (CAETANO et al., 2007; VILA; ROSSI, 2002; SALÍCIO; GAIVA, 2006).

Na UTI, o profissional de saúde lida com situações estressantes e de tensão, tais como: a escassez de leitos e de recursos humanos, e também, a dificuldade de aceitação da morte, podendo afetar a sua atuação e contribuindo para uma assistência mecanicista, descaracterizando o cuidado. (PADILHA; KIMURA, 2000)

Durante o período de hospitalização, os profissionais de saúde devem se preocupar com o processo de recuperação do paciente, contribuindo para a criação de um ambiente adequado e proporcionando a sensação de relacionamento com esse mundo e não de isolamento. (DIAS, 2006) O paciente idoso requer uma atenção especial, exige um cuidado diferenciado com maior sensibilidade, considerando suas peculiaridades, suas alterações orgânicas normais, psicológicas e sociais. Deve-se considerar que cada idoso percebe a sua condição de maneira diferente, pois alguns reagem individualmente ao sofrimento, exigindo do profissional a capacidade para intervir em momentos de crises. (BENINCÁ; FERNANDEZ; GRUMANN, 2005)

Por lidar constantemente com as perdas alheias, é necessário que a equipe aprenda a superá-las ou desenvolva mecanismos de adaptação, fortalecendo-se como pessoa para, dessa maneira, apoiar os pacientes e familiares nos momentos difíceis.

O papel do profissional de saúde não é só cuidar dos problemas fisiopatológicos, é também, compreender e assistir o idoso em sua totalidade, às questões psicossociais, ambientais e familiares, suprindo suas necessidades, garantindo a eficácia de sua recuperação. $O$ atendimento a esses idosos requer conhecimentos específicos da área, devendo saber agir diante das situações diferentes e inesperadas.

Falar em humanização pressupõe que, além de um atendimento digno, acolhedor e solidário pela equipe multidisciplinar para com o paciente, deve-se adotar uma postura ética que permeie todas as atividades profissionais. (BACKES; LUNARDI FILHO; LUNARDI, 
2005) Dor e sofrimento precisam ser reconhecidos e compreendidos de maneira humanizada para que o idoso perceba que todos têm um objetivo comum: atendê-lo e satisfazê-lo.

A humanização no atendimento exige dos profissionais de saúde, essencialmente, compartilhar com o seu paciente experiências e vivências que resultem na ampliação do foco de suas ações, via de regra restritas ao cuidar como sinônimo de ajuda às possibilidades da sobrevivência. Dessa forma, cada encontro entre o profissional e o paciente reveste-se de uma tomada de consciência quanto aos valores e princípios norteadores de suas ações, num contexto relacional. (PESSINI; BERTACHINI, 2004) A capacidade e o interesse na comunicação entre equipe e família são considerados essenciais no cuidado humanizado. É através da comunicação que somos capazes de nos relacionarmos e construirmos uma condição de atendimento e interação com o outro, seja ele idoso ou colega de trabalho. (PROCHET; SILVA, 2008) Acolhendo o paciente idoso de maneira agradável, transmitindo sensação de segurança e a percepção de que ele é bem vindo, desta forma, os profissionais do hospital contribuem para a sua recuperação.

A construção de uma assistência humanizada na UTI torna-se uma tarefa difícil, pois

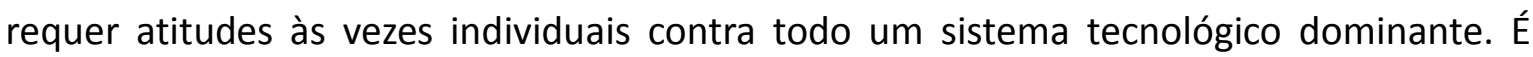
importante lembrar que é um processo com metas a curto/médio/longo prazo, impulsionada por medidas de avaliação e da capacidade de aprender com a própria experiência e a dos outros. Humanizar a relação com o paciente realmente exige que o profissional valorize a afetividade e a sensibilidade como elementos necessários ao cuidar.

O profissional de saúde deve ter em mente que quando se trabalha em uma UTI, depara-se com um ambiente de ansiedade. Procurar humanizá-la é tarefa diária, assim como reconhecer que sua presença se torna tão importante quanto os procedimentos realizados (VILA; ROSSI, 2002; SALÍCIO; GAIVA, 2006)

Um exemplo simples do processo de humanização, é promover a autonomia dos pacientes fazendo com que eles aos poucos reconquistem sua capacidade de resolução independente. Assim, o paciente passa a ser tratado como pessoa que é, com todos os tipos de sentimento que a interação pode suscitar, e não apenas como um doente. 


\title{
O cuidado humanizado
}

O termo cuidado deriva-se do antigo inglês "carion" e das palavras góticas "kara" ou "karon". Como substantivo, cuidado deriva-se de kara, que significa aflição, pesar ou tristeza. Como verbo "cuidar" (de carion) significa "ter preocupação por", ou "sentir uma inclinação ou preferência" ou ainda, "respeitar/considerar" no sentido de ligação, de afeto, amor, carinho e simpatia. (WALDOW, 1992)

\begin{abstract}
Humanizar o cuidar é dar qualidade à relação profissional da saúde - paciente. É acolher as angústias do ser humano diante da fragilidade de corpo, mente e espírito. Destaca-se nesse contexto a presença solidária do profissional com habilidade humana e científica. Diante do cotidiano desafiador pela indiferença crescente, a solidariedade e o atendimento digno com calor humano são imprescindíveis. Ser sensível à situação do outro, criando um vínculo, graças a uma relação dialogal, para perceber o querer ser atendido com respeito, numa relação de diálogo e de necessidades compartilhadas. (PESSINI; BERTACHINI, 2004)
\end{abstract}

Pode-se dizer também que esse cuidado, por parte de quem cuida, implica em compreender a pessoa em sua individualidade enfrentando desafios vivenciados no dia-adia. O cuidado exige doação, estar próximo, compartilhar sentimentos, criar espaço para ouvir e ser ouvido, e ter responsabilidade com o outro. Ele surge a partir do momento em que a existência de algo ou alguém possui importância para o outro. (CARNEIRO, 2008)

Neste contexto, os profissionais de saúde vêm buscando investigar o processo de envelhecimento com o intuito de compreender melhor esta fase do desenvolvimento humano com a finalidade de melhorar a qualidade de vida da pessoa idosa. (ARAÚJO; CARVALHO, 2004) Segundo Loureiro (2004), "a qualidade de vida compreende a boa saúde física e mental, o respeito, a dignidade, o acesso à informação, a consideração, o amor dos que as circundam".

Os profissionais de saúde devem procurar estabelecer uma comunicação efetiva com o paciente e a família, buscando auxiliá-los sempre que possível. A comunicação representa um dos instrumentos básicos para o cuidar, no qual poderá ajudar as pessoas envolvidas - paciente/família - a relatar seus problemas e procurar caminhos para enfrentá-los. Esta, é o meio pelo qual os profissionais expressam o seu cuidado, visando a recuperação e, em consequência, a satisfação de todos. Neste processo, particularmente em UTI, é importante levar em consideração que a experiência dos pacientes, é de um 
tratamento doloroso, invasivo e intensivo. O paciente internado nesta unidade pode encontrar-se numa situação de isolamento e quanto mais intensivo for o tratamento, menos efetivo parece ser o contato e a assistência da equipe, pois muitas vezes pouco toca, conversa e ouve o ser humano que está à sua frente. (BARLEM et al., 2008)

Levando em consideração a importância do processo de comunicação, esta parece ser o elo entre os profissionais e o idoso, permitindo a compreensão das necessidades implícitas ou explícitas que permeiam a relação.

A humanização do cuidado é uma temática que atualmente vem sendo discutida pelos profissionais de saúde, e o instrumento dessa humanização é a comunicação, como forma de contribuir para a melhoria da qualidade da assistência.

A comunicação é um ato criativo, não existe apenas um agente emissor ou receptor, mas uma troca entre pessoas, isto é, um processo recíproco que provoca mudanças na forma de sentir, pensar e atuar dos envolvidos. Assim, estando internado em uma UTI ou não, o paciente deve ser reconhecido como sujeito do cuidado, sendo assegurado sempre que possível, seu direito às escolhas e decisões, a partir do que ele acredita e deseja para si. (PONTES; LEITÃO; RAMOS, 2008)

Uma vez que o idoso é admitido na UTI, devem ser disponibilizados todos os recursos de suporte à vida, os quais otimizam o seu tratamento. (SITTA; JACOB FILHO, 2002)

A humanização depende de nossa capacidade de falar e ouvir, do diálogo com nossos semelhantes. Faz-se necessário olhar para si e para o outro, na tentativa de que o autoconhecimento colabore positivamente no cuidado de cada ser. Por isso é tão importante conhecermos a nós mesmos, sabermos o que é bom e o que não é bom, aprender a respeitar a individualidade, a saber reconhecer-se na situação do outro. (CARVALHO et al. , 2005; MOTA; MARTINS; VERAS, 2006)

Segundo BOFF, "cuidar é mais que um ato, é uma atitude. Do ponto de vista existencial, o cuidado se acha a priori, antes de toda atitude e situação do ser humano, o que sempre significa dizer que ele se acha em toda atitude e situação de fato." (BOFF, 2004) 
O cuidar não é fácil, pois requer condições satisfatórias para que de fato esse cuidado possa acontecer com qualidade já que se vivencia com os limites humanos, a vida e a morte.

Numa relação de cuidado, o cuidar do outro implica dedicação, atenção, reflexão, além da prática efetiva, o saber cuidar promove estreitamento dos vínculos interpessoais para minimizar as condições de sofrimento físico-mental. Nesse processo, é importante que haja qualidade envolvendo os profissionais de saúde que cuidam e o paciente que está sendo cuidado. (CARVALHO et al., 2005; LIMA; TEIXEIRA, 2007; PINHO; SANTOS, 2008)

Para que aconteça a humanização no atendimento, é preciso que a equipe de saúde esteja preparada para fazer seu diferencial no ato do cuidado, visto que suas ações são fruto de um elo empático entre paciente e profissional. (COREN, 2002)

\section{Acolhimento}

"Acolher significa oferecer ou obter refúgio, proteção, ou conforto físico; proteger, abrigar, amparar". Acolher significa receber, recepcionar e, também, aceitar o outro como sujeito de direitos e desejos e como co-responsável pela produção da saúde, tanto na perspectiva individual como do ponto de vista coletivo. (HENNINGTON, 2005)

Ao acolher, cria-se um vínculo entre a família/paciente e profissionais de saúde, gerando entre quem cuida e quem é cuidado uma relação humanizada. $\mathrm{O}$ acolhimento visa à identificação das necessidades do paciente/família, a valorização das suas queixas, o respeito às diferenças, tornando-se assim imprescindível no cuidado em saúde e objeto da prática de toda a equipe. (GARANHANI et al., 2008)

O paciente idoso hospitalizado necessita do acolhimento e de ter alguém com quem possa expressar e dividir seus temores que ali o cercam. A equipe de saúde precisa identificar as ansiedades, angústias e medos, para serem traçadas estratégias adequadas a essas situações. Percebe-se que o idoso demanda atendimento diferenciado com o intuito de promover um restabelecimento mais digno, em consequência do adoecimento provocado pelo processo de envelhecimento. (LUSTOSA, 2007) A presença da família é extremamente eficaz no período de internação para a recuperação do paciente idoso, pois presta apoio emocional e transmite segurança. 
Diante de uma situação estressante, os familiares podem se sentir angustiados, desamparados e com dificuldades para reagirem à nova situação e de que modo enfrentála. A equipe nesse momento tem papel fundamental no apoio familiar, atendendo a todos, ouvindo seus pedidos e assumindo uma postura capaz de acolher, escutar, dando esclarecimentos às necessidades surgidas.

O acolhimento é um processo de mudança para humanização no atendimento, fazendo com que o foco de trabalho da equipe multiprofissional seja o doente, não só a doença. $O$ estímulo à capacitação desses profissionais faz com que assumam uma postura acolhedora, possibilitando a ampliação e efetivação deste cuidado. O acolher não é simplesmente receber bem e nem apenas uma etapa, inclui todo o desenvolvimento do processo de trabalho em saúde. (SILVA; ALVES, 2008; MARTINS; NASCIMENTO et al., 2008; INOJOSA, 2005)

O acolhimento é condição fundamental para o diálogo, para o encontro entre equipe e cliente, é uma relação humanizadora, de trocas, de respeito às diferenças, sendo imprescindível para a formação do vínculo entre as pessoas envolvidas. (MARTINS et al., 2008)

Para que se estabeleça o acolhimento, é necessário um ambiente acolhedor, uma postura responsável e confiável de toda a equipe. Para que aconteça a valorização do outro, é necessário a presença, a escuta, permitindo desta forma, um atendimento com maior resolutividade e responsabilização. Sabe-se que, na prática, estão pouco presentes na rotina do trabalho dos profissionais nos vários serviços de saúde.(FRANCO, 1999; MATUMOTO, 1998)

No cotidiano da UTI, observa-se as necessidades e dificuldades enfrentadas pela equipe de saúde destacando o estresse como fator dominante, aliado à intensa atividade destes profissionais devido às condições normalmente críticas dos pacientes idosos, se caracterizando como um ambiente de alta complexidade e cuidado.

Para acolher é necessário ser acolhido, reorganizando o próprio processo de trabalho, buscando alterar as relações entre equipes/clientes e das equipes entre si, visando garantir o atendimento humanizado.

As dificuldades existem e são conhecidas, mas a força de vontade de cada um, a qualificação e capacitação profissional, a postura adequada, podem facilitar e garantir, 
com eficácia, atendimento a todos, de forma humanizada e qualificada. (ECHER et al., 1999)

\section{Considerações Finais}

Diante do exposto sobre humanização em UTI, observou-se a necessidade do profissional de saúde adotar uma postura empática diante do cuidado oferecido ao paciente idoso, garantindo conforto, resolutividade, buscando assistência numa visão holística.

Foi possível observar que a internação em uma UTI desencadeia sentimentos de insegurança e sofrimento tanto para o paciente idoso como para família.

$\mathrm{Na}$ UTI, com todos os recursos tecnológicos existentes, os profissionais não devem esquecer que jamais a máquina substituirá o trabalho humano, especialmente nos momentos de fragilidade, onde a vida, que é o bem maior, deve ser sempre o principal foco da atenção.

Para tanto, é necessário criar condições que facilitem as ações de cuidado, capacitando e motivando estes profissionais, promovendo um bom relacionamento entre família, paciente e equipe de saúde.

Para obter uma comunicação satisfatória e prestar um cuidado humanizado, é preciso que todos os profissionais se envolvam e acreditem que sua presença é tão importante quanto a realização de procedimentos técnicos. A comunicação apresenta-se como um componente do cuidado, de grande importância para o paciente, transmitindo segurança, respeito e carinho.

$\mathrm{Na}$ assistência de qualidade, constatou-se que o acolhimento tem uma grande importância no processo de trabalho em saúde, com o objetivo de proporcionar o bem estar físico, emocional e psicológico das pessoas envolvidas, enfatizando atitudes acolhedoras da equipe multiprofissional.

Promover um atendimento acolhedor ao paciente idoso e a seus familiares é garantir um atendimento de qualidade, estabelecendo relações humanizadas entre quem cuida e quem é cuidado.

Desta forma, espera-se que o presente estudo venha alertar aos profissionais de saúde sobre a necessidade de mudança no seu modo de agir, sobretudo no ambiente de 
terapia intensiva, proporcionando aos pacientes uma assistência mais digna e humanizada.

\section{Referências}

ALVAREZ, A.M. Tendo que cuidar: a vivência do idoso e de sua família cuidadora no processo de cuidar e ser cuidado em contexto domiciliar. Florianópolis: UFSC, 2001. Disponível em: <www.bases.bireme.br>. Acesso em: 24 set. 2009.

ARAÚJO, L.F.A.; CARVALHO, V.A.M.L. Velhices: estudo comparativo das sociais entre idosos de grupos de convivência. Texto Envelhecimento, Rio de Janeiro, v.7, n.,1, p., 57-75, 2004. Disponível em: <ww.scielo.br>. Acesso em: 26 ago. 2009.

BACKES, D.S.; LUNARDI , V.L.; LUNARDI FILHO, W.D. A humanização hospitalar como expressão da ética. Revista Latino-Americana de Enfermagem, Ribeirão Preto, 2006. Disponível em: <www.eerp.usp.br>. Acesso em: 24 ago.2009.

BACKES, D.S.; LUNARDI FILHO, W.D.; LUNARDI, V.L. A construção de um processo interdisciplinar de humanização à luz de Freire. Texto \& Contexto Enfermagem, Florianópolis, v.3, 2005. Disponível em: <www.scielo.br>. Acesso em: 11 ago.2009.

BARLEM, B.L.D.; ROSENHEIN, D.P.N.; LUNARDI, V.L.; LUNARDI FILHO, W.D. Comunicação como instrumento de humanização do cuidado de enfermagem: experiências em unidade de terapia intensiva. Revista Eletrônica de Enfermagem, Goiânia, 2008. Disponível em: <www.fen.ufg.br/revista/v10/n4>. Acesso em: 6 set.2009.

BENINCÁ, C.R.; FERNANDEZ, M.; GRUMANN,C. Cuidado e morte do idoso no hospital: vivência da equipe de enfermagem. Revista Brasileira de Ciências do Envelhecimento Humano, Passo Fundo, 2005. Disponível em: <www.upf.edu.br>. Acesso em: 29 set. 2009.

BOFF, L. Saber Cuidar: ética do humano -compaixão pela terra. In: BOFF, L. Cuidado: o ethos do humano. 11. ed. Rio de Janeiro: Vozes, 2004. p.33-39.

BRASIL. Lei no 8842, de 4 de janeiro de 1994. Dispõe sobre a Política Nacional do Idoso, cria o Conselho Nacional do Idoso e dá outras providências. Disponível em: <www.dhnet.org.br>. Acesso em: 24 set. 2009.

BRASIL. Ministério da Saúde. Secretaria de Atenção à Saúde. Núcleo Técnico da Política Nacional de Humanização. Acolhimento nas práticas de produção de saúde. 2. ed. Brasília (DF), 2006 Disponível em: <www.saude.rr.gov.br>. Acesso em: 26 ago.2009.

CAETANO, J.; ANDRADE, L.; SOARES, E.; PONTE, R. Cuidado humanizado em terapia intensiva: um estudo reflexivo. Revista de Enfermagem, 2007. Disponível em: $<w w w . b a s e s . b i r e m e . b r>$. Acesso em: 13 maio 2009.

CARNEIRO, T.M. Vivenciando o cuidar e o curar como familiar em um hospital. Revista Brasileira de Enfermagem, Brasília, v.61, n.3, 2008. Disponível em: <www.scielo.br>. Acesso em: 1 set.2009. 
CARVALHO, A.R.S.; PINHO, M.C.V.; MATSUDA, L.M.; SCOCHI, M.J. Cuidado e humanização na enfermagem: reflexão necessária. In: SEMINÁRIO NACIONAL ESTADO E POLÍTICAS SOCIAIS NO BRASIL, 2., 2005, Cascavel. Anais... Cascavel, 2005. Disponível em: <www.cacphp.unioeste.br/projetos>. Acesso em: 4 jun.2009.

COREN, SP. A arte como ferramenta na humanização hospitalar. Revista COREN-SP, São Paulo, n.42, set.2002. Disponível em: <www.coren-sp.gov.br>. Acesso em: 9 jun.2009.

DANTAS, J.; SILVA, E.M.; LOURDES, M.C. Lazer e sexualidade no envelhecer humano. Disponível em: <www.redadultosmayores.com.br>. Acesso em: 23 set. 2009.

DIAS, M.A.A. Humanização do espaço hospitalar: uma responsabilidade compartilhada. $O$ Mundo da Saúde, São Paulo, ano 30, v.30, n.2, 2006. Disponível em:

$<w w w . s c a m i l o . e d u . b r>$. Acesso em: 30 ago.2009.

ECHER, I.C.; ONZI, M.R.; CRUZ, A.M.P.; BEN, G.M; FERNANDES, T.S.; BRUXE, V.M. Opinião de visitantes sobre a sistemática de visitação a pacientes internados em unidade de terapia intensiva. Revista Gaúcha de Enfermagem, Porto Alegre, v. 20, n. 1, p. :57-68, jan. 1999. Disponível em: <www.bases.bireme.br>. Acesso em: 3 jun.2009.

FAQUINELLO, P.; COLLET, N. Vínculo afetivo mãe/criança na unidade de alojamento conjunto pediátrico. Revista Gaúcha de Enfermagem, Porto Alegre, v. 24, n. 3, p. 294-304, ago. 2009. Disponível em: <www.scielo.br>. Acesso em: 11 ago.2009.

FAQUINELLO, P.; HIGARASHI, I.H.; MARCON, S.S. O atendimento humanizado em unidade pediátrica: percepção do acompanhante da criança hospitalizada. Texto Contexto Enfermagem. Florianópolis, 2007. Disponível em: <www.scielo.br/pdf/tce/v6n4 >.Acesso em: 11 ago.2009.

FRANCO, T.B.; BUENO, W.S.; MERHY, E.E. O acolhimento e o processo de trabalho em saúde: o caso de Betim. Caderno de Saúde Pública, v.15, n.2, 1999. Disponível em: $<w w w . s c i e l o b r a s i l . b r>$. Acesso em: 6 jan.2009.

GARANHANI, M.L.; MARTINS, J.T.; ROBAZZI, M.L.C.C.; GOTELIPE, I.C. O trabalho de enfermagem em unidade de terapia intensiva: significados para técnicos de enfermagem. Revista Eletrônica Saúde Mental Álcool e Drogas, Ribeirão Preto, v. 4, n. 2, 2008.

Disponível: <www.pepsic.bvs-psi.org.br> Acesso em: 30 ago.2009.

HENNINGTON, E.A. Acolhimento como prática interdisciplinar num programa de Extensão Universitária. Cadernos de Saúde Pública, Rio de Janeiro, v. 21, p. 256-65, jan./fev. 2005.

IBGE. Diretoria de Pesquisas. Coordenação de População e Indicadores Sociais. Gerência de Estudos e Análises da Dinâmica Demográfica. Projeção da população do brasil por sexo e idade para o período 1980-2050. 2004. Disponível em: <www.ibge.gov.br>. Acesso em: 13 set. 2009.

INOJOSA, R.M. Acolhimento: a qualificação do encontro entre profissionais de saúde e usuários. In: CONGRESSO INTERNACIONAL DEL CLAD SOBRE LA REFORMA DEL ESTADO Y DE LA ADMINISTRACIÓN PÚBLICA, 10., 2005, Chile. Disponível em: $<w w w . b r e s s e r p e r e i r a . o r g . b r>$. Acesso em: 14 jun.2009. 
KNOBEL, E.; NOVAES, M.A.F.P.; BORK, A.M.G.T. Humanização dos CTIs. In: KNOBEL, E. et al. Condutas no paciente grave. 2.ed. São Paulo: Ateneu, 1998. p.1306-1312.

LEITE, M.A.; VILA, V.S.C. Dificuldades vivenciadas pela equipe multiprofissional na Unidade de Terapia Intensiva. Revista Latino Americana de Enfermagem, Ribeirão Preto, 2005. Disponível em: <www.scielo.br> Acesso em: 1 set.2009.

LIMA, R.M.T.; TEIXEIRA, E.R. A vivência de quem cuida em terapia intensiva e suas implicações psicoafetivas. Revista de Enfermagem UERJ, Rio de Janeiro, 2007. Disponível em: <www.bases.bireme.br>. Acesso em: 04 jun.2009.

LOPES, M.J.M.; LAUFERT, L. A saúde das trabalhadoras da saúde: algumas questões. In: HHAAG, G.S.; LOPES, M.J.; SCHUCK, J.S. A enfermagem e a saúde dos trabalhadores. Goiânia: AB, 2001.

LUSTOSA, M.A. Atendimento ao paciente idoso. Revista da SBPH, Rio de Janeiro, v.10, n.2. 2007. Disponível em: <www.pepsic.bvs-psi.org.br>. Acesso em: 3 out.2009.

MARTINS, J.J; NASCIMENTO, E.R.P. Repensando a tecnologia para o cuidado do idoso em UTI. Disponível em: <www.bases.bireme.br>. Acesso em: 24 set.2009.

MARTINS, J.J.; NASCIMENTO, E.R.P.; GEREMIAS, C.K.; SCHNEIDER, D.G.; SCHWEITZER, G.; NETO, H.M. O acolhimento à família na Unidade de Terapia Intensiva: conhecimento de uma equipe multiprofissional. Revista Eletrônica de Enfermagem, Goiânia, v.10, n.4, 2008. Disponível em: <www.fen.ufg.br/revista/v10/n4/v10n4a22>. Acesso em: 31 maio 2009.

MATUMOTO, S. O acolhimento: um estudo sobre seus componentes e sua produção em uma unidade de rede básica de serviços de saúde. 1998. Dissertação (Mestrado) - Escola de Enfermagem de Ribeirão Preto, Ribeirão Preto. Disponível em: <www.lappis.org.br>. Acesso em: 28 maio2009.

MOTA, R.A.; MARTINS, C.G.M.; VERAS, R.M. Papel dos profissionais de saúde na política de humanização hospitalar. Psicologia em Estudo, Maringá, v.11, n.2, maio/ago. 2006. Disponível em: <www.scielo.br>. Acesso em: 21 maio2009.

PADILHA, K.G.; KIMURA, M. Aspectos éticos da prática de enfermagem em Unidade de Terapia Intensiva. Sobeti em Revista, São Paulo, 2000. Disponível em: <www.scielo.br>. Acesso em: 2 set.2009.

PEDREIRA, L.C. O cuidado heideggeriano e assistência ao idoso na UTI. Nursing, n. 42, p. 23-25, nov.2001. Disponível em: <www.utp.br>. Acesso em: 24 set.2009.

PESSINI, L.; BERTACHINI, L. Humanização e cuidados paliativos. São Paulo: Loyola, 2004.

PINHO, L.B.; SANTOS, S.M.A. Dialética do cuidado humanizado na UTI: contradições entre o discurso e a prática profissional do enfermeiro. Revista da Escola de Enfermagem da USP, São Paulo, 2008. Disponível em: <www.ee.usp.br>. Acesso em: 30 maio2009. 
PONTES, A.C.; LEITÃO, I.M.T.A.; RAMOS, I.C. Comunicação terapêutica em enfermagem: instrumento essencial do cuidado. Revista Brasileira de Enfermagem, Brasília, 2008. Disponível em: <www.scielo.br>. Acesso em: 6 set.2009.

PROCHET, T.C.; SILVA, M.J.P. Situações de desconforto vivenciadas pelo idoso hospitalizado com a invasão do espaço pessoal e territorial. Revista de Enfermagem, 2008. Disponível em: <www.eean.ufrj.br/revista_enf>. Acesso em: 29 set. 2009.

PROCHNOW, A.G.; SANTOS, J.L.G.; PRADEBON, V.M.; SCHIMITH, M.D. Acolhimento no âmbito hospitalar: perspectivas dos acompanhantes de pacientes hospitalizados. Revista Gaúcha de Enfermagem, Porto Alegre, 2009. Disponível em: <www.seer.ufrgs.br>. Acesso em: 26 ago.2009.

SALíCIO, D.M.B.; GAIVA, M.A.M. O significado de humanização da assistência para enfermeiros que atuam em UTI. Revista Eletrônica de Enfermagem, Goiânia, v. 8, n. 3, 2006. Disponível em: <www.fen.ufg.br/revista/revista8>. Acesso em: 12 mai.2009.

SCHNEIDER, D.G.; MANSCHEIN, A.M.M.; AUSEN, M.A.B.; MARTINS, J.J; ALBUQUERQUE, G..L. Acolhimento ao paciente e família na unidade coronariana. Texto \& Contexto Enfermagem, Florianópolis, 2008. Disponível em: <www.scielo.br/pdf/tce/v17n1/09>. Acesso em: 26 ago.2009.

SILVA, L.G.; ALVES, M.S. O acolhimento como ferramenta de práticas inclusivas de saúde. Revista APS, Porto Alegre, v.11, n.1, jan./mar.2008. Disponível em:

$<w w w . b a s e s . b i r e m e . b r>$. Acesso em: 4 jun.2009.

SILVA, M.J.P. Qual o tempo do cuidado? humanizando os cuidados de enfermagem. In: Humanizando os cuidados de enfermagem. São Paulo: Loyola, 2004. p.180.

SITTA, M.C.; JACOB FILHO, W.J. O idoso no centro de terapia intensiva. In: FREITAS, et.al. Tratado de geriatria e gerontologia. Rio de Janeiro: Guanabara Koogan, 2002. p.740-2.

VILA, V.S.C.; ROSSI, L.A. O significado cultural do cuidado humanizado em Unidade de Terapia Intensiva: "muito falado e pouco vivido." Revista Latino-americana de enfermagem, Ribeirão Preto, v.10, n.2, mar 2002. Disponível em: $<w w w . s c i e l o b r a s i l . c o m . b r>$. Acesso em: 15 maio 2009.

WALDOW, V.R. Cuidar: uma revisão teórica. Revista Gaúcha Enfermagem, Porto Alegre, 1992. Disponível em: www.pos.ufsc.br - Acesso em: 04 set. 2009. 